\title{
Scale-dependent spatial patterns in benthic communities around a tropical
} island seascape

Aston, Eoghan A.; Williams, Gareth J.; Green, J.A. Mattias; Davies, Andrew J.; Wedding, Lisa M.; Gove, Jamison M.; Jouffray, Jean-Baptiste; Jones, Timothy T.; Clark, Jeanette

\section{Ecography}

\section{DOI:}

10.1111/ecog.04097

Published: 01/03/2019

Peer reviewed version

Cyswllt i'r cyhoeddiad / Link to publication

Dyfyniad o'r fersiwn a gyhoeddwyd / Citation for published version (APA):

Aston, E. A., Williams, G. J., Green, J. A. M., Davies, A. J., Wedding, L. M., Gove, J. M., Jouffray, J-B., Jones, T. T., \& Clark, J. (2019). Scale-dependent spatial patterns in benthic communities around a tropical island seascape. Ecography, 42(3), 578-590. https://doi.org/10.1111/ecog.04097

\footnotetext{
Hawliau Cyffredinol / General rights

Copyright and moral rights for the publications made accessible in the public portal are retained by the authors and/or other copyright owners and it is a condition of accessing publications that users recognise and abide by the legal requirements associated with these rights.

- Users may download and print one copy of any publication from the public portal for the purpose of private study or research.

- You may not further distribute the material or use it for any profit-making activity or commercial gain

- You may freely distribute the URL identifying the publication in the public portal ?
}

Take down policy

If you believe that this document breaches copyright please contact us providing details, and we will remove access to the work immediately and investigate your claim. 
Scale-dependent spatial patterns in benthic communities around a tropical island seascape

Eoghan A. Aston ${ }^{1 \S}$, Gareth J. Williams ${ }^{1}{ }^{*}$, J. A. Mattias Green ${ }^{1}$, Andrew J. Davies ${ }^{1}$, Lisa M. Wedding ${ }^{2}$ Jamison M. Gove ${ }^{3}$, Jean-Baptiste Jouffray ${ }^{4}$, Timothy T. Jones ${ }^{5}$, Jeanette Clark ${ }^{3}$

${ }^{1}$ School of Ocean Sciences, Bangor University, Anglesey LL59 5AB, UK

${ }^{2}$ Center for Ocean Solutions, Stanford University, Stanford, CA 94305 USA

${ }^{3}$ NOAA Pacific Islands Fisheries Science Center, Honolulu, 96818 Hawaii, USA

${ }^{4}$ Stockholm Resilience Centre, Stockholm University, Stockholm 106 91, Sweden

${ }^{5}$ School of Aquatic and Fishery Sciences, University of Washington, Seattle, USA

*Corresponding author, Email: g.j.williams@bangor.ac.uk, Tel: +44(0)1248 382588, Orchid ID: 0000-0001-7837-1619

§authors contributed equally to this work 


\section{Abstract}

Understanding and predicting patterns of spatial organization across ecological communities is central to the field of landscape ecology, and a similar line of inquiry has begun to evolve sub-tidally among seascape ecologists. Much of our current understanding of the processes driving marine community patterns, particularly in the tropics, has come from small-scale, spatially-discrete data that are often not representative of the broader seascape. Here we expand the spatial extent of seascape ecology studies and combine spatiallyexpansive in situ digital imagery, oceanographic measurements, spatial statistics, and predictive modeling to test whether predictable patterns emerge between coral reef benthic competitors across scales in response to intra-island gradients in physical drivers. We do this around the entire circumference of a remote, uninhabited island in the central Pacific (Jarvis Island) that lacks the confounding effects of direct human impacts. We show, for the first time, that competing benthic groups demonstrate predictable scaling patterns of organization, with positive autocorrelation in the cover of each group at scales $<\sim 1 \mathrm{~km}$. Moreover, we show how gradients in subsurface temperature and surface wave power drive spatially-abrupt transition points in group dominance, explaining $48-84 \%$ of the overall variation in benthic cover around the island. Along the western coast, we documented ten times more sub-surface cooling-hours than any other part of the coastline, with events typically resulting in a drop of $1-4^{\circ} \mathrm{C}$ over a period of $<5 \mathrm{hr}$. These high frequency temperature fluctuations are indicative of upwelling induced by internal waves and here result in localized nitrogen enrichment $\left(\mathrm{NO}_{2}\right.$ $+\mathrm{NO}_{3}$ ) that promotes hard coral dominance around $44 \%$ of the island's perimeter. Our findings show that, in the absence of confounding direct human impacts, the spatial organization of coral reef benthic competitors are predictable and somewhat bounded across the seascape by concurrent gradients in physical drivers. 
Keywords: benthic competition; coral reef; internal wave; nutrients; seascape ecology; spatial scaling; spatial clustering; subsurface temperature; upwelling; wave power

\section{Introduction}

Landscape ecology, the study of spatial patterning and its ecological consequences, has been key in changing the way we understand and ultimately manage ecosystems (Wiens 2009). The field often emphasizes the scale-dependence of spatial patterns and has fundamentally changed the way ecologists understand their linkages to ecological processes at broad geographic extents. For example, landscape-level data from terrestrial ecosystems have revealed how plant and forest communities respond to long-term biophysical gradients (Thomas et al. 2013) and environmental disturbance (Turner et al. 1997, Turner et al. 1994), which can drive spatial heterogeneity in competitive dominance among species (Kellner and Asner 2014). Importantly, a spatially-explicit understanding of how landscape patterning influences ecological processes (McGarigal and Marks 1995) has greatly aided terrestrial land-use management, by informing the preservation of landscape diversity, reducing habitat fragmentation, and halting the spread of disturbance (Botequilha Leitão and Ahern 2002).

With new terrestrial ecological paradigms catalyzed by the analysis of broad spatial data, the application of such approaches in the marine realm shows great promise (Pittman et al. 2011, Wedding et al. 2011). Seascape ecology is focused on understanding the causes and ecological consequences of spatial patterning in the marine environment, often at multiple scales (Pittman 2017, Pittman et al. 2011). Seascape ecologists have capitalized on geospatial technology such as airborne imagery (Mumby et al. 1998), high-resolution seafloor mapping (Hitt et al. 2011, Wedding et al. 2008), and more recently, in situ photogrammetry (Edwards et al. 2017) in combination with spatial pattern metrics to expand our understanding of marine spatial ecology across scales (Wedding et al. 2011). For example, in the Hawaiian 
Islands the arrangement and composition of seafloor topography, benthic community cover, and wave exposure are important predictors of coral reef fish assemblages (Friedlander et al. 2003, Wedding et al. 2008). The patterns in the distribution and abundance of marine fishes are evident across multiple spatial scales, as coral reef ecosystems demonstrate spatial heterogeneity at centimeter (Barott et al. 2012), meter (Richardson et al. 2017) and kilometer scales (Gove et al. 2015). However, the spatial scales at which biophysical drivers influence and predict coral reef benthic community seascapes has not been as well studied, and a multiscaled approach is needed to understand the resulting spatial patterns and processes (Williams et al. 2015a).

Inter-island biophysical gradients can set natural bounds on the abundance of key benthic competitors on coral reefs (Jouffray et al. 2015, Williams et al. 2015a). Similar structuring forces and environmental constraints exist at intra-island scales (Gove et al. 2015, Williams et al. 2013). For example, at Palmyra Atoll, an uninhabited coral reef atoll in the central Pacific, intra-island gradients in surface wave power lead to predictable spatial patterns in benthic communities at scales of 1-10s km (Gove et al. 2015). Where wave power peaks, benthic competitors with wave tolerant, low-lying morphologies such as turf algae and crustose coralline algae (CCA) dominate. Where wave power is low, larger upright benthic competitors such as hard corals and macroalgae that are vulnerable to physical dislodgement and damage from water-borne projectiles (Engelen et al. 2005, Madin 2005, Madin et al. 2014) can gain competitive dominance (Gove et al. 2015). Importantly, by adopting a seascape ecology approach, Gove et al. (2015) revealed gradients in wave power to be associated with spatially distinct benthic community patterns, such as a quadrant-like structure in macroalgal abundance around Palmyra's coastline. Additionally, hard coral cover at Palmyra also becomes more spatially clustered with increasing wave energy (Williams et al. 2013), suggesting surface waves play an important role in determining both community 
dominance (Bradbury and Young 1981, Dollar 1982, Page-Albins et al. 2012) and the spatial distribution of benthic competitors across the coral reef seascape. Whether similar seascape spatial patterns of benthic communities emerge in response to gradients in other physical drivers at other coral reef islands and atolls, however, remains untested.

Here we asked whether predictable seascape patterns emerge between benthic competitors in response to intra-island gradients in physical drivers around the circumference of a tropical island. Our working hypothesis was inspired by previous work documenting strong intra-island gradients in subsurface temperature as a result of localized upwelling at Jarvis Island in the central Pacific Ocean (Gove et al. 2006). One common physical method by which water can be upwelled from the deep to the shallows around coral reefs atolls, islands, and coastal reefs is by internal waves (Gove et al. 2016). Internal waves are the subsurface analogue to surface waves, but instead of acting on the sea-surface they exist on density surfaces within the water column. Instead of breaking on shorelines and beaches, they break at depth when they encounter rough topography (Alford et al. 2015). Internal waves are thus capable of forcing deep cold water up through the thermocline and in to the shallows, and with them carrying nutrients to oligotrophic shallow reef communities (Leichter et al. 2012, Wang et al. 2007, Williams et al. 2018). We hypothesized the gradients in subsurface temperature invoked by localized upwelling around Jarvis's coastline would result in concurrent gradients in nutrient availability, offering an opportunity to test what effect this has on benthic community seascapes.

Localized increases in nutrient supply are reported to have wide-ranging and contrasting effects on the ecology of tropical reefs (D'Angelo and Wiedenmann 2014, Norström et al. 2016). For example, enhanced nutrient concentrations in concert with diminished herbivorous fish stocks can suppress coral growth and promote fleshy macroalgae dominance (McClanahan et al. 2003, Smith et al. 2010). In contrast, increased nutrient supply 
to shallow reefs by physical processes such as internal waves and current-driven upwelling can enhance coral growth (Leichter and Salvatore 2006) and promote hard coral persistence over time (Wang et al. 2007). These seemingly contrasting scenarios are hypothesized, in part, to be driven by variations in the source and type of nutrients in question, for example naturally upwelled nutrients versus human-derived agricultural run-off (D'Angelo and Wiedenmann 2014). Jarvis Island thus presented an opportunity to test whether localized natural nutrient-enrichment results in distinct and predictable patterns of benthic community organization across scales, while accounting for concurrent gradients in surface wave power. Importantly, using Jarvis allowed us to examine the effects of gradients in nutrient availability on benthic community seascapes in the absence of confounding direct human impacts that can act to obscure and distort natural biophysical relationships on coral reefs (Williams et al. 2015a).

\section{Methods}

\section{Study Site}

Jarvis Island $\left(0^{\circ} 22^{\prime} \mathrm{S} 160^{\circ} 01^{\prime} \mathrm{W}\right)$ is an uninhabited, U.S-affiliated coral reef island in the Line Islands Archipelago, Pacific Ocean (Fig.1a). The reefs surrounding Jarvis are protected under U.S. federal law as part of the Pacific Remote Islands Marine National Monument. Situated 2,420 km south of the Hawaiian Archipelago, Jarvis was acknowledged as one of the 'healthiest' coral reefs in the world by the Ocean Health Index (Halpern et al. 2012). As such, it supports a relatively high biomass of herbivorous and piscivorous fish $\left(>100 \mathrm{~g} \mathrm{~m}^{-2}\right.$ ) relative to populated islands within the region (Williams et al. 2015b). However, Jarvis also suffered extensive coral mortality following a mass coral bleaching event associated with the 2015/16 El Niño (Brainard et al. 2018), making the dissemination of 
patterns and drivers of benthic condition before this event particularly timely and important to prevent shifting baselines (Knowlton and Jackson 2008).

As with other equatorial Pacific islands, Jarvis experiences a relatively low seasonal sea-surface temperature range of $\sim 1^{\circ} \mathrm{C}$ (Gove et al. 2013). Mean sea-surface temperature near Jarvis is $\sim 27^{\circ} \mathrm{C}$ (Gove et al. 2013) and is typically unchanged until $\sim 100 \mathrm{~m}$ depth, at which point the temperature rapidly drops off to between $12-13^{\circ} \mathrm{C}$ by $\sim 200 \mathrm{~m}$ depth (Fig. $1 \mathrm{c}$ ). Surface $\mathrm{NO}_{3}$ concentrations in the island's vicinity are nearly an order of magnitude higher $\left(\sim 5 \mu \mathrm{mol} \mathrm{l}^{-1}\right)$ than the "typical" upper limit for most coral reefs (Atkinson and Falter 2003) and rapidly increase below the $\sim 100 \mathrm{~m}$ thermocline, equaling $20 \mu \mathrm{mol} \mathrm{l}^{-1}$ by $\sim 200 \mathrm{~m}$ depth (Fig.1c). Nearshore seawater temperatures at Jarvis exhibit a pronounced cross-island, westeast gradient due to island blocking of the cold, nutrient rich, eastward flowing subsurface Equatorial Undercurrent (EUC) (Gove et al. 2006). This cross-island gradient varies year-toyear owing to the El Niño Southern Oscillation (ENSO), but in general causes the western side of the island to be $0-5{ }^{\circ} \mathrm{C}$ colder than the east (Karnauskas et al. 2016). To test our hypothesis that this intra-island temperature gradient driven by localized upwelling results in a concurrent nutrient gradient (specifically deep-water derived nitrogen), we collected water samples using a hand deployed $5 \mathrm{~L}$ Niskin bottle string at depths of 10 and $20 \mathrm{~m}$ (to match the depths of our benthic surveys - see below) at numerous sites around the island's perimeter in 2006 (Fig. 1a). Water samples $(100 \mathrm{ml})$ were immediately pulled from each Niskin and frozen at $-20^{\circ} \mathrm{C}$. The concentration of total nitrogen $\left(\mathrm{NO}_{2}+\mathrm{NO}_{3}\right)$ in each sample was later quantified at NOAA’s Pacific Marine Environmental Laboratories.

\section{Benthic community surveys and spatial processing}

Benthic community data were collected via towed-diver surveys (Kenyon et al. 2006) in March to April of 2006, 2008, and 2010. Divers were towed with instrumented boards at $\sim 3 \mathrm{~km} \mathrm{~h}^{-1}$ suspended $\sim 1 \mathrm{~m}$ above the benthos at a target depth of $15 \mathrm{~m}$. The tow boards were 
equipped with a high-resolution digital SLR camera (Canon EOS 10-D/50-D) and strobes to illuminate the benthos. Position information was recorded using an onboard Global Positioning System (GPS); a layback model accurately georeferenced each photograph. In each survey year, the divers circumnavigated 100\% of Jarvis's perimeter, taking images approximately every $15 \mathrm{~m}$ along the $12.4 \mathrm{~km}$ linear distance of fore reef (the reef slope habitat that is exposed to the open ocean). Benthic images were subsequently filtered to only include those images within the $8-20 \mathrm{~m}$ depth zone to allow comparability with previous studies in the region (Gove et al. 2015, Williams et al. 2015). This resulted in a total of 2,397 images, with 1,867 of those images occurring within $5 \mathrm{~m}$ of the $15 \mathrm{~m}$ target depth. The percent cover of five functional groups, namely hard coral (split in to four morphological subcategories: plating, branching, free living, and digitate), crustose coralline algae (CCA), macroalgae, turf algae, and soft coral was extracted using Coral Point Count software with Excel extensions (Kohler and Gill 2006). Due to the extremely low percentage cover of some benthic functional groups (all $<5 \%$ at an island-mean scale within each of the three survey years), only plating hard coral, CCA, macroalgae, and turf algae were investigated further in this study.

We divided Jarvis' fore reef habitat into 111 discrete grid cells (each $\sim 112 \mathrm{~m}$ wide) around the circumference of the island in ArcGIS (v10.5, custom Python script: https://doi.org/10.5281/zenodo.1199350) and spatially assigned each benthic image to one of these discrete cells. We arrived at this number of cells through a selective process aiming to balance the width and number of cells with the proportion of cells that subsequently contained benthic images, setting a threshold of $>50 \%$ of the cells needing to contain images across the three survey years at the smallest cell width. Data from all three years were used to calculate an overall mean cover for each functional group within each grid cell. To be included in subsequent statistical analyses, cells had to contain $\geq$ four benthic images in each 
of the three survey years, resulting in 71 grid cells with data from a total of 1,781 benthic images.

\section{Subsurface temperature (proxy for localized upwelling)}

In addition to the camera and strobes, the tow boards were equipped with a SeaBird ${ }^{\mathrm{TM}}$ Electronics (SBE) 39 subsurface pressure, temperature-depth recorder (STR), set at a $10 \mathrm{~s}$ sample rate $\left(0.002^{\circ} \mathrm{C}\right.$ accuracy). This approach gave a spatially expansive, high-resolution, but snapshot view of in situ reef-level temperature gradients around Jarvis during each of the three survey years.

To quantify longer-term intra-island gradients in reef-level temperature, we used five SBE 39 STRs that recorded every 15-30 min (then averaged at hourly intervals to allow comparison) between 2004 and 2010. The STRs were mounted to the reef substrate at 10-15 $\mathrm{m}$ depth and captured all four major cardinal directions around the circumference of Jarvis (Fig.2a). Using these data, we calculated the time period (in hours) that the reef experienced significant cooling as a result of deep, cooler water being driven up the reef slope. In summary, the hourly temperature data were interpolated to 5-min intervals using linear interpolation to facilitate a more accurate estimation of the termination time of a cold-water pulse event. A rapid decrease in the recorded temperature was interpreted as a cold-water event if it fulfilled two conditions: (1) the rate of change of the temperature has to be larger than $-0.3^{\circ} \mathrm{C}$ per $5 \mathrm{~min}$, and (2) the overall temperature decrease within the pulse had to be more than $0.3^{\circ} \mathrm{C}$ (compared to the temperature before the pulse began) (Sevadjian et al. 2012, Williams et al. 2018). A cold-water pulse was assumed to have ended when the temperature had increased to half that of the total temperature drop. Because our focus here was on tidally-driven (M2) pulses, a pulse was discarded if it lasted for longer than 13 hours. The magnitude of cold pulses was calculated by finding the minimum value in the cumulative 
sum of the cold pulse and calculated as a percentage of the long-term climatological temperature range of Jarvis from Gove et al. (2013).

\section{Surface wave power}

Integrated surface wave power $\left(\mathrm{kWhr} \mathrm{m}^{-1}\right)$ was calculated for all grid cells using a 3-h output from NOAA’s Wave Watch III global, full-spectral wave model (WWIII; http://polar.ncep.noaa.gov/waves/wavewatch). To link the 50-km resolution WWIII model output to island grid cells, we used an incident wave swath method. First, we calculated wave power from significant wave height $\left(H_{s}\right)$, peak period $\left(T_{p}\right)$ and peak direction $\left(D_{p}\right)($ Tolman 2014). Wave power $\left(\mathrm{W} \mathrm{m}^{-1}\right)$ is the energy flux per unit of wave crest, defined as:

$$
W P=\frac{\rho g^{2} T_{p} H_{s}^{2}}{64 \pi}
$$

where $\rho$ is the density of seawater $\left(1024 \mathrm{~kg} \mathrm{~m}^{-3}\right)$ and $g$ is the acceleration of gravity $\left(9.8 \mathrm{~m} \mathrm{~s}^{-}\right.$ ${ }^{2}$ ). Wave power combines wave height and period and thus provides a more representative metric of the most powerful wave events than either $\mathrm{H}_{\mathrm{s}}$ or $\mathrm{T}_{\mathrm{p}}$ alone. For 25 equally spaced locations (every $497 \mathrm{~m}$ ) around the circumference of Jarvis, we created a $360^{\circ}$ radial plot of line length $100 \mathrm{~km}$. Where these lines intersected land on Jarvis itself that degree bin was removed, leaving only the angles open to exposure in the incident wave swath. For each of these exposed degree bins, wave power and its corresponding direction were selected at each time-step for the closest WWIII pixel. We summed yearly values for the period $2000-2010$ to give a single number representing the mean annual cumulative wave power, or the annual wave energy flux $\left(\mathrm{kWhr} \mathrm{m}^{-1}\right)$ and calculated a yearly average for each of the 25 equally spaced locations. The next step was to create a $250 \mathrm{~m}$ buffer around each of our 25 locations and used a spatial join to assign their wave power values to individual grid cells. When grid cells contained values from more than one $250 \mathrm{~m}$ buffer, an average was taken. 


\section{Quantifying benthic functional group spatial autocorrelation across scales}

To test the hypothesis of no spatial autocorrelation in the cover of each benthic group around the circumference of Jarvis, we used the Moran's I statistic (Moran 1950). Using the R programming language (R Development Core Team, www.r-project.org), we coded a custom function based on the Moran.I function in the ape package (Paradis et al. 2004) to calculate the observed Moran's I value (OMI) based on an inverse Euclidean distance matrix defined as:

$$
I=\frac{n}{S_{0}} \frac{\sum_{i=1}^{n} \sum_{j=1}^{n} \omega_{i, j}\left(x_{i}-\bar{x}\right)\left(x_{j}-\bar{x}\right)}{\sum_{i=1}^{n}\left(x_{i}-\bar{x}\right)^{2}}
$$

where $\mathrm{n}$ is the number of observations, $\omega_{i, j}$ is a matrix of weights between observations, $x_{i}$ is the observed value at location $i, \bar{x}$ is the mean value and $S_{0}$ is the sum of spatial weights $S_{0}=$ $\sum_{i=1}^{n} \sum_{j=1}^{n} \omega_{i, j}$. In this function the spatial weights are defined as the inverse of the minimum distance, $d_{i, j}$, around an island (i.e. along the fore reef habitat circumference) between locations $i$ and $j$, as follows:

$$
\begin{gathered}
d_{i, j}=\min ((j-i),(n+i-j)) \\
\omega_{i, j}=\frac{1}{d_{i, j}} \text { for } i \neq j, 0 \text { otherwise }
\end{gathered}
$$

A significant departure from random $(p<0.05)$ indicated spatial patterns in abundance to be highly organized in space (i.e., among grid cells). Specifically, positive OMI values indicated spatial clustering, with the more positive the OMI value the more positively autocorrelated the data.

We explored patterns of spatial autocorrelation over a range of scales, by rescaling the data within a moving window at increasing $100-\mathrm{m}$ increments to a maximum of $2 \mathrm{~km}$. Grid cells containing 'no data' (i.e., those that did not meet our criteria of $\geq 4$ benthic images in 
each of the three survey years) were not included in the averaging process. Beyond our smallest spatial resolution of $100 \mathrm{~m}$, there were multiple starting points for the moving window averaging process. To account for this, we computed all possible starting points around the island for each re-scaling exercise (i.e., phase), calculating the OMI and $p$-value for each. Our outputs report the mean OMI and the minimum and maximum OMI values for each scale as a function of the phase and the scale at which the upper bound of $p$ exceeds 0.05 .

\section{Predictive modeling of benthic seascapes}

To link spatial changes in benthic cover between island grid cells to concurrent changes in our two focus physical drivers (subsurface temperature and surface wave power), we used boosted regression tree (BRT) modeling. Unlike many modeling techniques that aim to fit a single parsimonious model, BRT modeling incorporates machine learning decision tree methods (Breiman 2001) and boosting, a method to reduce predictive error (Elith et al. 2008), to build an additive regression model in which individual terms are simple trees, fitted in a forward stage-wise manner. Tree-based ensemble techniques, such as boosted regression trees have frequently been used to model species-seascape relationships at a range of spatial scales (Knudby et al. 2010, Leathwick et al. 2006, Pittman et al. 2009).

The in situ STR loggers, while useful for quantifying long-term intra-island gradients in cooling hours, did not provide sufficient spatial coverage to be included in a BRT modeling framework. Instead, to represent intra-island subsurface temperature gradients we used the data collected by the towed-diver STR during their complete circumnavigation of the island. Data from all three survey years within the depth range $8-20 \mathrm{~m}$ were used to calculate an average subsurface temperature for each island grid cell. Our two predictors, 
surface wave power and subsurface temperature, had a Pearson's correlation coefficient of 0.53. Both were therefore included in the model fitting process.

BRT models and graphical outputs were constructed using the R packages $g b m$ (Ridgeway 2017), the gbm.step function in the dismo package (Hijmans et al. 2017), and a series of custom coded functions to link the BRT outputs to the package ggplot2. Benthic percent cover values were arcsine transformed to achieve normality and modeled using a Gaussian distribution. We used 10-fold cross validation for model development and validation, and this approach allowed us to sub-sample the data multiple times during model development, helping to reduce spatial autocorrelation in the response variable (sensu Gove et al. 2015). We then calculated the overall cross-validation percent deviance explained by each model as a metric of model performance. To optimize predictive performance, we varied three parameters: the bag-fraction ( $b f$, proportion of data to be selected at each step), learning rate ( $l r$, used to shrink the contribution of each tree as it is added to the model), and tree complexity ( $t c$, the number of nodes in a tree). Using a customized loop routine (Richards et al. 2012), we identified the combination of these three parameters that resulted in the lowest cross validation deviance (CVD) over $b f$ values $0.5,0.7$, and $0.8, l r$ values $0.001,0.0001$, and 0.00001 , and $t c$ values $1-5$, while maintaining a minimum of $\geq 1000$ fitted trees (with the final optimal number of trees determined by gbm.step). The relative importance of sub-surface temperature and surface wave power in predicting spatial variations in benthic cover was quantified by the number of times each was selected for splitting, weighted by the squared improvement to the model as a result of each split, and averaged over all trees (Friedman and Meulman 2003). We visualized the conditional relationship the two predictors had on each response variable using partial dependency plots and calculated $95 \%$ confidence intervals from 10,000 bootstrapped replicates to visualize the uncertainty in our fitted functions (Buston and Elith 2011). 


\section{Results}

\section{Benthic community seascapes}

Across all three survey years $(2006,2008,2010)$, the island-mean $( \pm 1 \mathrm{SE})$ cover of hard coral equaled $25.0 \%( \pm 2.3)$ and was overwhelmingly dominated by plating coral $(22.4 \%$ $\pm 2.2)$. The island-mean cover of crustose coralline algae (CCA) equaled $21.7 \%( \pm 1.2)$ macroalgae equaled $17.1 \%( \pm 1.6)$, and turf algae equaled $23.1 \%( \pm 1.0)$. At intra-island scales, the four benthic functional groups exhibited clear spatial segregation regarding their spatial dominance. The dominance of plating coral occurred as a single zone along the entire west coastline, extending from approximately the central south coast to $\sim 5.5 \mathrm{~km}$ to the northwest (Fig. 2a) and reaching upward of $60-80 \%$ cover along the west to the northwest portion of the coastline (Fig. 3). In contrast, macroalgae displayed two spatial zones of dominance; one $\sim 2 \mathrm{~km}$ along the north to northeast portion of coastline (Fig. 2a) and peaking at $40-60 \%$ cover (Fig. 3), the other extending across $\sim 1 \mathrm{~km}$ of the southern coast (Fig. 2a) reaching between $20-40 \%$ cover (Fig. 3). CCA also displayed two spatial zones of dominance; one $\sim 1 \mathrm{~km}$ zone extending along half of the northeast coast and reaching upward of $40 \%$ cover, and a larger $\sim 1.7 \mathrm{~km}$ zone along the east to southeast coast, peaking at $20-$ 40\% cover (Fig. 2a, Fig. 3). Finally, turf algae displayed more erratic spatial dominance, existing as a relatively short $(<1 \mathrm{~km})$ portion of the east coast (Fig. $2 \mathrm{a})$ and reaching upwards of $40 \%$ cover (Fig. 3$)$, but also occurring in small pockets $(100-200 \mathrm{~m}$ wide) interspersed among the plating coral and macroalgal zones along the south coast and within the north coast macroalgal zone (Fig. 2a).

All four benthic functional groups showed significant signs of positive autocorrelation (spatial clustering) at the smallest scale resolution of the data (i.e., 100 m, Fig. 4). Above this scale, all four groups showed a decline in positive autocorrelation. The cover of plating coral 
was spatially clustered up until $1100 \mathrm{~m}$, at which point patterns did not differ significantly from random (Fig. 4a). In contrast, the cover of macroalgae became spatially random at almost half this scale at $600 \mathrm{~m}$ (Fig. 4b). The cover of CCA and turf algae showed an almost identical drop in positive autocorrelation between scales of $100-900 \mathrm{~m}$, at which point the spatial cover of both groups did not differ significantly from random (Fig. 4c-d).

\section{Intra-island gradients in subsurface temperature, nutrients, and surface wave power}

There was considerable intra-island variability in the number of tidally-driven subsurface cooling hours between 2004 and 2010 (Fig. 2 b-f). STR-b, located on the southwest tip of Jarvis in the center of the plating coral dominance zone, experienced the highest number of cooling hours overall $(\sim 6 \%$ of the time there was a pulse present at STRb), with the majority of events lasting between $1-2 \mathrm{hr}$ (Fig. 2b). Here, the subsurface temperature dropped by up to $4^{\circ} \mathrm{C}$, suggestive of water originating from between $100-150$ $\mathrm{m}$ depth (Fig. 1c). STR-c, located further to the northwest within the plating coral dominance zone, also recorded a relatively high number of cooling hours compared to all other STRs ( $3 \%$ of the time, Fig. $2 \mathrm{c})$. However, STR-c was only operational for less than four out of the six years. Given the close correlation between STR-b and STR-c for those periods of time that there was temporal overlap (between 2004 and 2007, Fig. 2b-c), the number of cooling hours at STR-c likely represents an underestimate for this region of the coastline. The total number of cooling hours recorded by the remaining three STRs located on the north, east, and south cardinal points of the coastline were negligible, and those events that did occur were of a low magnitude (generally $<1{ }^{\circ} \mathrm{C}$, Fig. 2 d-f). This intra-island gradient in subsurface cooling hours was reflected in a mean drop in subsurface temperature of $\sim 1^{\circ} \mathrm{C}$ recorded by the toweddiver STR along the west to the northwest coast relative to the rest of the island (Fig. $2 \mathrm{~g}$ ). As we predicted, total nitrogen $\left(\mathrm{NO}_{2}+\mathrm{NO}_{3}\right)$ was subsequently higher along the western coast 
relative to the north, east, or southern coast (Fig. 1b). Mean annual cumulative wave power was lowest along the west to the northwest region $\left(\sim 60,000 \mathrm{kWhr} \mathrm{m}^{-1}\right)$, then steadily increased in a clockwise direction, peaking in the northeast to east at $\sim 140,000 \mathrm{kWhr} \mathrm{m}^{-1}$, before dropping steadily again along the south coast towards the west (Fig. $2 \mathrm{~g}$ ).

\section{Predicting benthic community seascapes}

Surface wave power and subsurface temperature were strong predictors of spatial variations in the percent cover of benthic functional groups around the circumference of Jarvis, explaining $84 \%$ of the total cross-validation percent deviance in plating coral, $72 \%$ in macroalgae, $63 \%$ in crustose coralline algae (CCA), and $48 \%$ in turf algae (Table 1). Of the two predictors, subsurface temperature was by far the stronger predictor of spatial variations in benthic cover, with a relative influence score $>78 \%$ for all benthic groups (Table 1) and resulting in more pronounced functional relationships in the partial dependency plots (Fig. 5). Plating coral cover was negatively related to subsurface temperature and surface wave power (Fig. 5a-b), peaking where temperature equaled $\sim 25.8-26.1^{\circ} \mathrm{C}$ and where there was lower wave power, before rapidly dropping in cover above $26.4^{\circ} \mathrm{C}$ (Fig. 5a). At the point along the temperature gradient that plating coral cover began to drop, competitive macroalgae cover started to rapidly increase, peaking at $\sim 26.6^{\circ} \mathrm{C}$ and at intermediate wave power (Fig. 5c-d). CCA cover was positively related to both subsurface temperature and surface wave power (Fig. 5e-f), with cover rapidly increasing above $\sim 26.2^{\circ} \mathrm{C}$. Turf algae cover was also positively related to subsurface temperature, showing a similar pattern to that of the macroalgae, and increasing in cover rapidly above $26.1^{\circ} \mathrm{C}$ (Fig. $5 \mathrm{~g}$ ). Turf algae cover also showed a slight decrease at the point along the surface wave power gradient that CCA began to increase (Fig. 5h); however, the relationship was unpronounced and contributed relatively little to overall model performance (Table 1). 


\section{Discussion}

Seascapes occur at many physical scales and are defined by the species and ecological processes relevant to the research question(s) (Wedding et al. 2011). As a result, the concept of scaling in landscape ecology does not focus on the human perception of the correct scale, instead it is defined by the organisms' use of the environment in space and time (Wiens and Milne 1989). We show that coral reef benthic functional groups demonstrate predictable scaled patterns of organization across the seascape of a remote tropical island, with positive autocorrelation present within each group at scales $<\sim 1 \mathrm{~km}$. Although there is no single scale that can be defined as characteristic for seascape ecology (Pittman and McAlpine 2003), we have identified the importance of scale-dependent spatial patterns in competing coral reef benthic functional groups. Moreover, the strong spatial clustering of benthic groups across the seascape forms a somewhat simplistic pattern of intra-island spatial dominance that is predicted by concurrent gradients in physical drivers.

\section{Benthic community spatial patterns and their drivers across a coral reef seascape}

Spatial pattern metrics provide a consistent method with which to compare seascape pattern, structure, and to evaluate changes across the seascape at a range of spatial scales (Botequilha Leitão et al. 2006). Previous works on coral reefs have used seascape models to show that wave power and depth can provide refuges from fishing pressure and that these spatial pattern metrics are able to predict fish assemblage structure in other reef locations (Stamoulis et al. 2018). Here, we advanced the application of spatial pattern metrics across coral reef seascapes to include subsurface temperature and surface wave power and coupled those with spatially-expansive digital benthic image surveys. Importantly, we did this in an area free from direct local human impacts that can decouple natural biophysical relationships 
on coral reefs (Williams et al. 2015a), thus offering insight in to the natural spatial structuring forces of coral reef benthic community seascapes.

Around the $12.4 \mathrm{~km}$ of Jarvis Island's circumference, we found distinct spatial transition points between expanses of coastline dominated by a single benthic group (Fig. 2a). Such spatially-abrupt transition points between distinct ecological communities are evident in numerous terrestrial and aquatic ecosystems, such as tropical rainforests, lakes, and estuaries (Attrill and Rundle 2002). Often the transition in question is between vastly different systems, for example the progression of lower montane rainforest to tropical rainforest along an altitudinal gradient in temperature and moisture (Whittaker 1970), or a shift from subtropical mangrove to a seagrass habitat (Hammerschlag et al. 2010). We observed a similar spatial scaling around a tropical island but evidenced by more subtle transitions in functional group dominance. We propose that the abrupt spatial transition points between competing benthic functional groups around the coastline occur as a result of biological limitations and emerging competitive dominance to intra-island gradients in physical drivers. Each of our four benthic functional groups showed evidence of spatial clustering (positive autocorrelation) at the $0.1 \mathrm{~km}$ scale resolution of our data. At increasing spatial scales, the level of positive autocorrelation decreased, but groups showed evidence of significant spatial clustering up until a scale of $0.6 \mathrm{~km}$ (for macroalgae), $0.9 \mathrm{~km}$ (for CCA and turf algae), and $1.1 \mathrm{~km}$ (for hard plating coral). Above these scales the cover of each functional group appeared spatially random (Fig. 4). Interestingly, the patterns of spatial autocorrelation around Jarvis appear comparable to Palmyra Atoll situated $\sim 720 \mathrm{~km} \mathrm{NNW}$ of Jarvis, where similar benthic functional groups showed evidence of positive autocorrelation across the seascape and also appeared spatially random at scales $>500 \mathrm{~m}$ (Gove et al. 2015). This common scaling between Jarvis and Palmyra, despite their geographical separation, suggests coral reef benthic seascapes may have important elements of spatial predictability. 
Previous work at Palmyra has documented biologically driven non-random spatial patterns of corals within $10 \times 10 \mathrm{~m}$ quadrats, owing to differences in the reproductive strategies of common reef-building corals (Edwards et al. 2017). While these biological drivers of spatial patterning are likely to also operate at smaller spatial scales at Jarvis, at the scales of community organization we describe (100s m), the patterns suggest an exogenous environmental structuring force. Indeed, we found gradients in subsurface temperature (as a proxy for upwelling and thus nutrient availability), and to a lesser extent surface wave power, to explain between $48-84 \%$ of the cross-validation percent deviance in functional group cover around Jarvis's coastline (Table 1).

We documented up to 10 times more cooling-hours within any given year along the western coast of Jarvis compared to the northern, eastern, or southern coasts, with events typically resulting in a drop of $1-4^{\circ} \mathrm{C}$ over a period of $<5 \mathrm{hr}$ (Fig. 2). These high frequency temperature fluctuations are indicative of upwelling induced by internal waves (Leichter et al. 2012, Williams et al. 2018, Wolanski et al. 2004, Wolanski and Delesalle 1995) and at Jarvis result in a peak in total nitrogen $\left(\mathrm{NO}_{2}+\mathrm{NO}_{3}\right)$ along the western coast relative to the other parts of the coastline (Fig. 1b). Excess nutrient delivery to oligotrophic shallow water coral reefs can result in macroalgal dominance, whether the nutrients are human-derived (D’Angelo and Wiedenmann 2014, McCook 1999) or naturally supplied by localized upwelling (Diaz-Pulido and Garzón-Ferreira 2002, Roberts et al. 1992, Wolanski et al. 1988). However, at Jarvis we found a strong positive spatial association between localized upwelling (captured in our spatial model by gradients in subsurface temperature) and hard coral dominance, predominantly a plating Montipora species that provides key three-dimensional reef structure along a $\sim 5.5 \mathrm{~km}$ section of the western coast. This positive spatial association was maximized in areas sheltered from high surface wave power. Powerful surface waves and their resulting bed-sheer stress can dislodge more three-dimensional coral growth forms 
(Madin et al. 2014) and instead tend to promote the dominance of low-lying coral morphologies, CCA, and turf algae (Bradbury and Young 1981, Gove et al. 2015, Williams et al. 2013).

The positive association between hard coral dominance and lower subsurface temperatures and increased nutrients along Jarvis's western coast may result from a number of factors. The functionally intact herbivorous reef fish communities at Jarvis (Williams et al. 2015b) likely provide essential top-down control of competitive algae that would otherwise benefit from increased nutrients and compete with corals for space (Barott et al. 2012, Smith et al. 2010). Also, increased nutrient concentrations can promote coral competitive dominance via increased coral growth rates and net primary production (D’Angelo and Wiedenmann 2014). This positive effect of increased nutrients to coral growth and persistence occurs under both experimental (Dunn et al. 2012) and natural field settings (Leichter and Salvatore 2006), including a positive effect of human-derived nutrients in some instances (Bongiorni et al. 2003). Corals are mixotrophic organisms that can exploit heterotrophic subsidies made available by physical processes such as upwelling (Roder et al. 2010, Williams et al. 2018). There are numerous physiological benefits of heterotrophic feeding to corals, including the increased storage of lipids that can promote their persistence during periods of stress and disturbance (Grottoli et al. 2006, Houlbreque and Ferrier-Pagès 2009). Such physiological benefits may help to explain the dominance of hard coral over our survey period along Jarvis's western coast where upwelling is most intense. Notably, however, these benefits did not result in resistance to a recent ocean warming event in 2016 that resulted in the temporary loss of current-driven upwelling and the near complete mortality of hard coral along Jarvis's entire western coastline (Brainard et al. 2018). Our data provide critical baseline information prior to this event, highlighting not only the patterns in benthic community structure across Jarvis's seascape, but also their physical driving forces. 
Whether the reefs return to the same spatial configuration around the island and whether they are once again predicted by concurrent gradients in physical processes remains to be seen.

\section{Conclusion}

Our study shows, for the first time, that competing coral reef benthic functional groups show a common scaling pattern of organization around a tropical island seascape. It also shows that, in the absence of confounding local human impacts, these patterns are highly predictable based on concurrent gradients in key physical drivers. These physical drivers actually originate far outside the system, generated by winds, prevailing ocean currents, and tides. It is not until they interact with island-scale features (bathymetry leading to upwelling) that they result in pronounced spatial organization of the benthic communities living there. This implies that at certain scales, the organization of coral reef benthic communities is bounded by the physical setting of the island and it is beyond our ability to manipulate and manage. Whether there exists some predictable common scaling law for coral reef benthic communities around tropical island seascapes remains to be seen and represents an exciting avenue for future research.

\section{References}

Alford, M. H. et al. 2015. The formation and fate of internal waves in the South China Sea. — Nature 521: 65-69.

Atkinson, M. J. and Falter, J. L. 2003. Coral Reefs. — In: Black, K. and Shimmield, G. (eds), Biogeochemistry of Marine Systems. CRC Press, pp. 40-64.

Attrill, M. J. and Rundle, S. D. 2002. Ecotone or Ecocline: Ecological Boundaries in Estuaries. — Estuar. Coast. Shelf Sci. 55: 929-936. 
Barott, K. et al. 2012. Natural history of coral-algae competition across a gradient of human activity in the Line Islands. - Mar. Ecol. Prog. Ser. 460: 1-12.

Bongiorni, L. et al. 2003. Survival, growth and gonad development of two hermatypic corals subjected to in situ fish-farm nutrient enrichment. - Mar. Ecol. Prog. Ser. 253: 137144.

Botequilha Leitão, A. and Ahern, J. 2002. Applying landscape ecological concepts and metrics in sustainable landscape planning. — Landscape Urban Plann. 59: 65-93.

Botequilha Leitão, A. et al. 2006. Measuring landscapes: a planner's handbook. — Island Press.

Bradbury, R. H. and Young, P. C. 1981. The effects of a major forcing function, wave energy, on a coral reef ecosystem. — Mar. Ecol. Prog. Ser. 5: 229-241.

Brainard, R. et al. 2018. Ecological impacts of the 2015/16 El Nino in the central equatorial Pacific [in "Explaining extreme events of 2016 from a climate perspective"]. — Bull. Am. Meteorol. Soc. 99: S21-S26.

Breiman, L. 2001. Statistical modeling: The two cultures. - Statistical Science 16: 199-215.

Buston, P. M. and Elith, J. 2011. Determinants of reproductive success in dominant pairs of clownfish: a boosted regression tree analysis. — J. Anim. Ecol. 80: 528-538.

D'Angelo, C. and Wiedenmann, J. 2014. Impacts of nutrient enrichment on coral reefs: new perspectives and implications for coastal management and reef survival. — Curr. Opin. Environ. Sustain. 7: 82-93.

Diaz-Pulido, G. and Garzón-Ferreira, J. 2002. Seasonality in algal assemblages on upwellinginfluenced coral reefs in the Colombian Caribbean. — Bot. Mar. 45: 284-292.

Dollar, S. J. 1982. Wave stress and coral community structure in Hawaii. - Coral Reefs 1: $71-81$ 
Dunn, J. G. et al. 2012. Effects of phosphate on growth and skeletal density in the scleractinian coral Acropora muricata: A controlled experimental approach. - J. Exp. Mar. Biol. Ecol. 411: 34-44.

Edwards, C. B. et al. 2017. Large-area imaging reveals biologically driven non-random spatial patterns of corals at a remote reef. - Coral Reefs

Elith, J. et al. 2008. A working guide to boosted regression trees. - J. Anim. Ecol. 77: 802813.

Engelen, A. H. et al. 2005. Effects of wave exposure and depth on biomass, density and fertility of the fucoid seaweed Sargassum polyceratium (Phaeophyta, Sargassaceae). — J. Phycol. 40: 149-158.

Friedlander, A. M. et al. 2003. Effects of habitat, wave exposure, and marine protected area status on coral reef fish assemblages in the Hawaiian archipelago. - Coral Reefs 22: 291-305.

Friedman, J. H. and Meulman, J. J. 2003. Multiple additive regression trees with application in epidemiology. — Stat. Med. 22: 1365-1381.

Gove, J. M. et al. 2016. Near-island biological hotspots in barren ocean basins. — Nat Commun 7: 10581.

Gove, J. M. et al. 2006. Temporal variability of current-driven upwelling at Jarvis Island. — J Geophys Res Oceans 111: C12011.

Gove, J. M. et al. 2013. Quantifying climatological ranges and anomalies for Pacific coral reef ecosystems. - PLoS One 8: e61974.

Gove, J. M. et al. 2015. Coral reef benthic regimes exhibit non-linear threshold responses to natural physical drivers. - Mar. Ecol. Prog. Ser. 522: 33-48.

Grottoli, A. G. et al. 2006. Heterotrophic plasticity and resilience in bleached corals. Nature 440: 1186-1189. 
Halpern, B. S. et al. 2012. An index to assess the health and benefits of the global ocean. Nature 488: 615-620.

Hammerschlag, N. et al. 2010. Relative predation risk for fishes along a subtropical mangrove-seagrass ecotone. — Mar. Ecol. Prog. Ser. 401: 259-267.

Hijmans, R. J. et al. 2017. Documentation on the R package "dismo" 1.1-4. See https://CRAN.R-project.org/package=dismo.

Hitt, S. et al. 2011. Diel movements of fishes linked to benthic seascape structure in a Caribbean coral reef ecosystem. — Mar. Ecol. Prog. Ser. 427: 275-292.

Houlbreque, F. and Ferrier-Pagès, C. 2009. Heterotrophy in tropical scleractinian corals. Biol. Rev. Camb. Philos. Soc. 84: 1-17.

Jouffray, J.-B. et al. 2015. Identifying multiple coral reef regimes and their drivers across the Hawaiian archipelago. — Philos. Trans. R. Soc. Lond., Ser. B: Biol. Sci. 370: 20130268

Karnauskas, K. B. et al. 2016. Mitigation of Coral Reef Warming Across the Central Pacific by the Equatorial Undercurrent: A Past and Future Divide. — Scientific Reports 6: 21213.

Kellner, J. R. and Asner, G. P. 2014. Winners and losers in the competition for space in tropical forest canopies. — Ecol. Lett. 17: 556-562.

Kenyon, J. C. et al. 2006. Towed-Diver Surveys, a Method for Mesoscale Spatial Assessment of Benthic Reef Habitat: A Case Study at Midway Atoll in the Hawaiian Archipelago. - Coast. Manage. 34: 339-349.

Knowlton, N. and Jackson, J. B. C. 2008. Shifting baselines, local Impacts, and global change on coral reefs. - PLoS Biol. 6: e54. 
Knudby, A. et al. 2010. Predictive mapping of reef fish species richness, diversity and biomass in Zanzibar using IKONOS imagery and machine-learning techniques. Remote Sens. Environ. 114: 1230-1241.

Kohler, K. E. and Gill, S. M. 2006. Coral Point Count with Excel extensions (CPCe): A Visual Basic program for the determination of coral and substrate coverage using random point count methodology. — Computers \& Geosciences 32: 1259-1269.

Leathwick, J. R. et al. 2006. Variation in demersal fish species richness in the oceans surrounding New Zealand an analysis using boosted regression trees. — Mar. Ecol. Prog. Ser. 321: 267-281.

Leichter, J. J. and Salvatore, J. 2006. Intermittent upwelling and subsidized growth of the scleractinian coral Madracis mirabilis on the deep fore-reef slope of Discovery Bay, Jamaica. — Mar. Ecol. Prog. Ser. 316: 95-103.

Leichter, J. J. et al. 2012. The island-scale internal wave climate of Moorea, French Polynesia. - J. Geophys. Res. (C Oceans) 117: C6.

Madin, J. S. 2005. Mechanical limitations of reef corals during hydrodynamic disturbances. - Coral Reefs 24: 630-635.

Madin, J. S. et al. 2014. Mechanical vulnerability explains size-dependent mortality of reef corals. - Ecol. Lett. 17: 1008-1015.

McClanahan, T. R. et al. 2003. Interaction between nutrients and herbivory in controlling algal communities and coral condition on Glover's Reef, Belize. - Mar. Ecol. Prog. Ser. 261: 135-147.

McCook, L. J. 1999. Macroalgae, nutrients and phase shifts on coral reefs: scientific issues and management consequences for the Great Barrier Reef. — Coral Reefs 18: 357367. 
McGarigal, K. and Marks, B. J. 1995. FRAGSTATS: spatial pattern analysis program for quantifying landscape structure. Gen. Tech. Rep. PNW-GTR-351. Portland, OR: U.S. Department of Agriculture, Forest Service, Pacific Northwest Research Station.

Moran, P. A. P. 1950. Notes on Continuous Stochastic Phenomena. - Biometrika 37: 17-23.

Mumby, P. J. et al. 1998. Digital analysis of multispectral airbourne imagery of coral reefs. — Coral Reefs 17: 59-69.

Norström, A. V. et al. 2016. Guiding coral reef futures in the Anthropocene. - Front. Ecol. Environ. 14: 490-498.

Page-Albins, K. N. et al. 2012. Patterns in Benthic Coral Reef Communities at Pearl and Hermes Atoll along a Wave-Exposure Gradient. — Pac. Sci. 66: 481-496.

Paradis, E. et al. 2004. APE: analyses of phylogenetics and evolution in R language. Bioinformatics 20: 289-290.

Pittman, S. J. 2017. Seascape Ecology. - Wiley Press.

Pittman, S. J. et al. 2009. Using Lidar Bathymetry and Boosted Regression Trees to Predict the Diversity and Abundance of Fish and Corals. - J. Coast. Res. 53: 27-38.

Pittman, S. J. et al. 2011. Practicing coastal seascape ecology. - Mar. Ecol. Prog. Ser. 427: 187-190.

Pittman, S. J. and McAlpine, C. A. 2003. Movements of marine fish and decapod crustaceans: process, theoryand application. — In: Southward, A. J. et al. (eds), Advances in Marine Biology, Vol. 44. Academic Press, Elsevier, pp. 205-294.

Richards, B. L. et al. 2012. Environmental factors affecting large-bodied coral reef fish assemblages in the Mariana Archipelago. — PLoS One 7: e31374.

Richardson, L. E. et al. 2017. Cross-scale habitat structure driven by coral species composition on tropical reefs. — Scientific Reports 7: 7557. 
Ridgeway, G. 2017. Generalized boosted regression models. Documentation on the R package 'gbm', version 2.1.3.

Roberts, H. H. et al. 1992. Biologic and geologic responses to physical processes: examples from modern reef systems of the Caribbean-Atlantic region. - Cont. Shelf Res. 12: 809-834.

Roder, C. et al. 2010. Trophic response of corals to large amplitude internal waves. - Mar. Ecol. Prog. Ser. 412: 113-128.

Sevadjian, J. et al. 2012. Shoreward advection of phytoplankton and vertical re-distribution of zooplankton by episodic near-bottom water pulses on an insular shelf: Oahu, Hawaii. — Cont. Shelf Res. 50: 1-15.

Smith, J. E. et al. 2010. The effects of top-down versus bottom-up control on benthic coral reef community structure. - Oecologia 163: 497-507.

Stamoulis, K. A. et al. 2018. Seascape Models Reveal Places to Focus Coastal Fisheries Management. - Ecol. Appl.

Thomas, R. Q. et al. 2013. Low mortality in tall tropical trees. — Ecology 94: 920-929.

Tolman, H. L. 2014. User manual and system documentation of WAVEWATCH III version 4.18. — NOAA / NWS / NCEP / MMAB Technical Note 316: pp194.

Turner, M. G. et al. 1997. Fires, Hurricanes, and Volcanoes: Comparing Large Disturbances. - Bioscience 47: 758-768.

Turner, M. G. et al. 1994. Effects of fire on landscape heterogeneity in Yellowstone National Park, Wyoming. — J. Veg. Sci. 5: 731-742.

Wang, Y. H. et al. 2007. Physical and ecological processes of internal waves on an isolated reef ecosystem in the South China Sea. — Geophys. Res. Lett. 34: L18609. 
Wedding, L. M. et al. 2008. Using bathymetric lidar to define nearshore benthic habitat complexity: Implications for management of reef fish assemblages in Hawaii. — Remote Sens. Environ. 112: 4159-4165.

Wedding, L. M. et al. 2011. Quantifying seascape structure extending terrestrial spatial pattern metrics to the marine realm. - Mar. Ecol. Prog. Ser. 427: 219-232.

Whittaker, R. H. 1970. Communities and Ecosystems. — Macmillan.

Wiens, J. A. 2009. Landscape ecology as a foundation for sustainable conservation. Landscape Ecol. 24: 1053-1065.

Wiens, J. A. and Milne, B. T. 1989. Scaling of 'landscapes' in landscape ecology, or, landscape ecology from a beetle's perspective. — Landscape Ecol. 3: 87-96.

Williams, G. J. et al. 2015a. Local human impacts decouple natural biophysical relationships on Pacific coral reefs. - Ecography 38: 751-761.

Williams, G. J. et al. 2018. Biophysical drivers of coral trophic depth zonation. - Mar. Biol. 165: 60.

Williams, G. J. et al. 2013. Benthic communities at two remote Pacific coral reefs: effects of reef habitat, depth, and wave energy gradients on spatial patterns. — PeerJ 1: e81.

Williams, I. D. et al. 2015b. Human, Oceanographic and Habitat Drivers of Central and Western Pacific Coral Reef Fish Assemblages. — PLoS One 10: e0120516.

Wolanski, E. et al. 2004. Large amplitude, leaky, island-generated, internal waves around Palau, Micronesia. — Estuar. Coast. Shelf Sci. 60: 705-716.

Wolanski, E. and Delesalle, B. 1995. Upwelling by internal waves, Tahiti, French Polynesia. — Cont. Shelf Res. 15: 357-368.

Wolanski, E. et al. 1988. Tidal jets, nutrient upwelling and their influence on the productivity of the alga Halimeda in the Ribbon Reefs, Great Barrier Reef. — Estuar. Coast. Shelf Sci. 26: 169-201. 


\section{Figures}
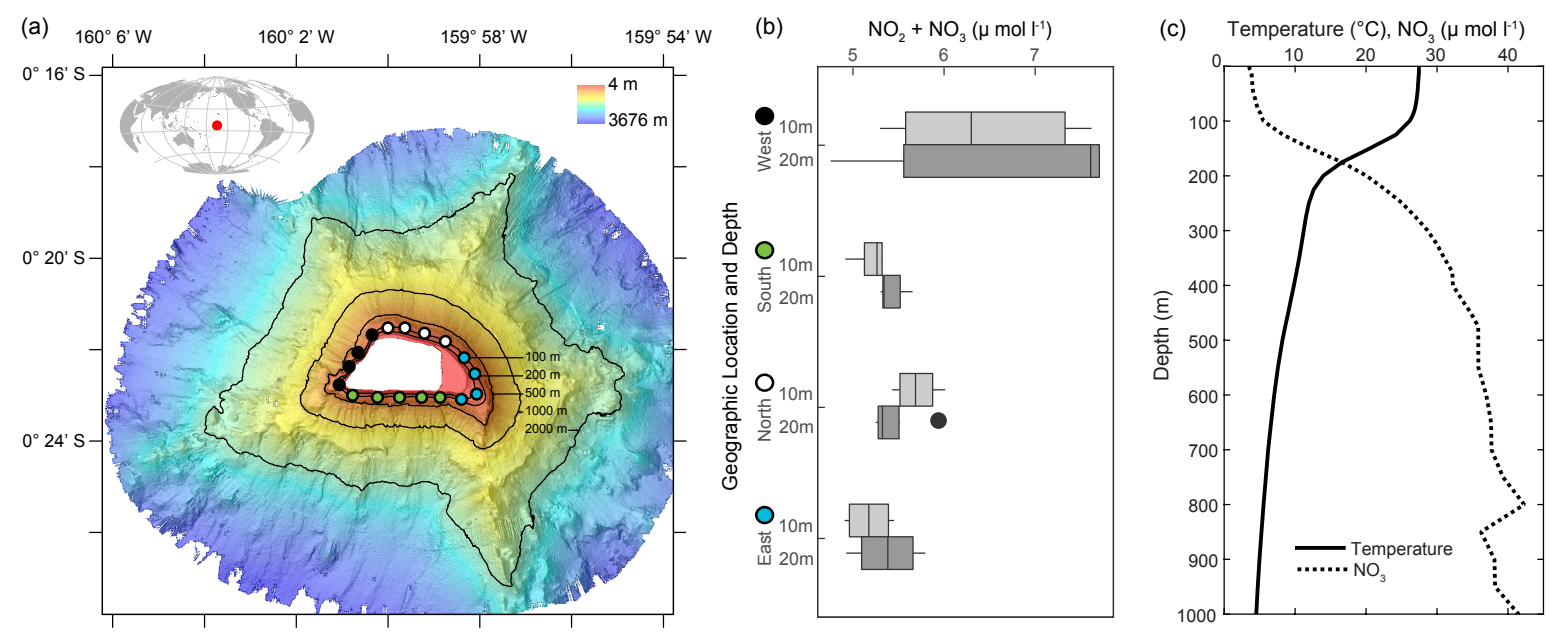

Figure 1. (a) Location of Jarvis Island in the Pacific Ocean and its surrounding bathymetry (20 $\mathrm{m}$ resolution, obtained from NOAA and the Joint Institute for Marine and Atmospheric Research, University of Hawaii). The location of water sampling stations for nutrient analyses are shown around the island. (b) Total nitrogen concentrations of the seawater along the western, northern, eastern and southern coasts of Jarvis Island at depths of 10 and $20 \mathrm{~m}$. (c) Vertical profiles of observed ocean temperature (solid) and nitrate concentrations (dotted) computed as a horizontal average from a $1^{\circ} \times 1^{\circ}$ box centered on the island. Data obtained from the World Ocean Atlas (https://www.nodc.noaa.gov/OC5/woa13/). 
(a)

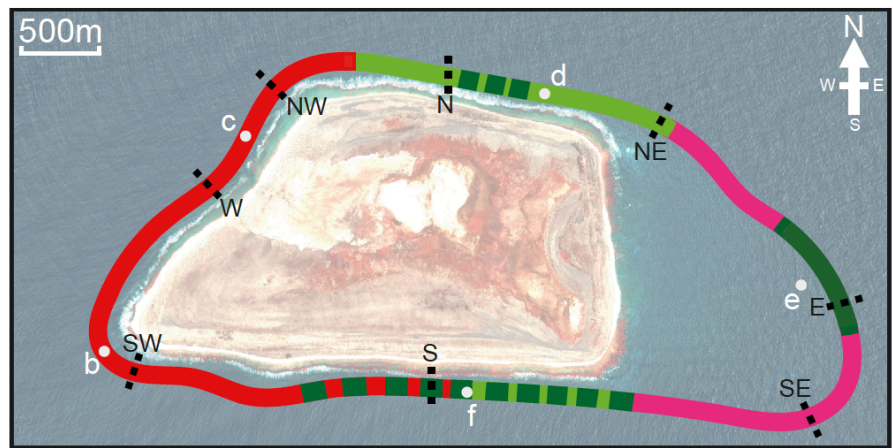

(b)
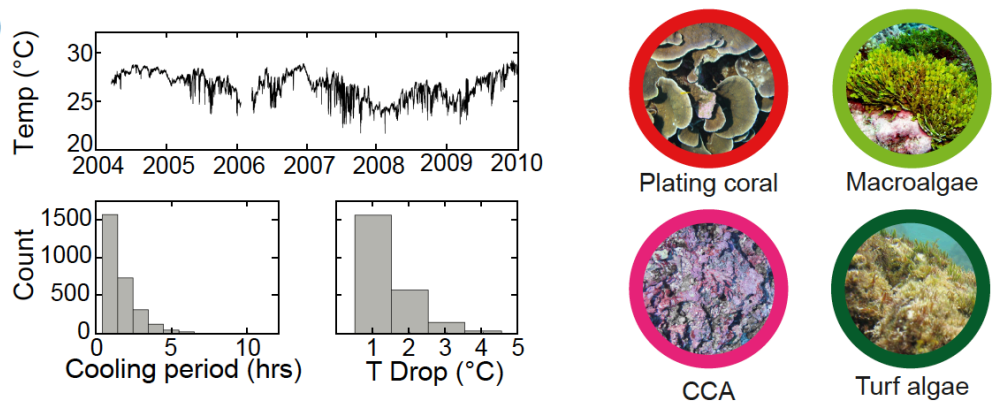

(c)
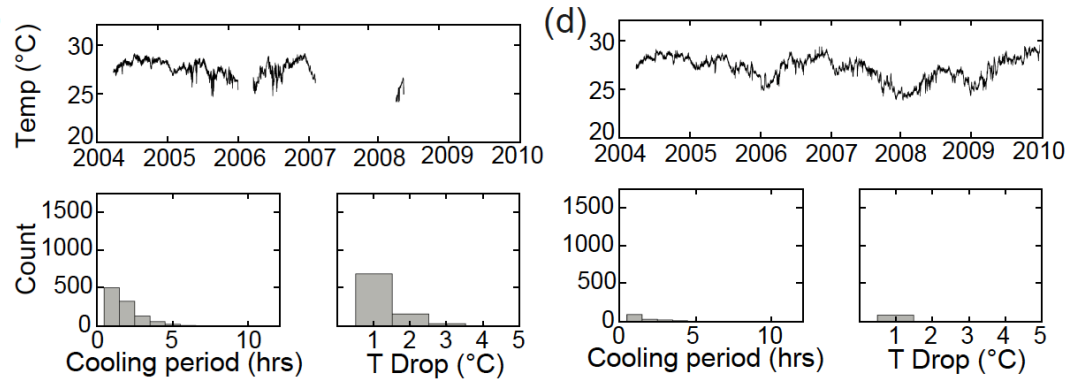

(e)
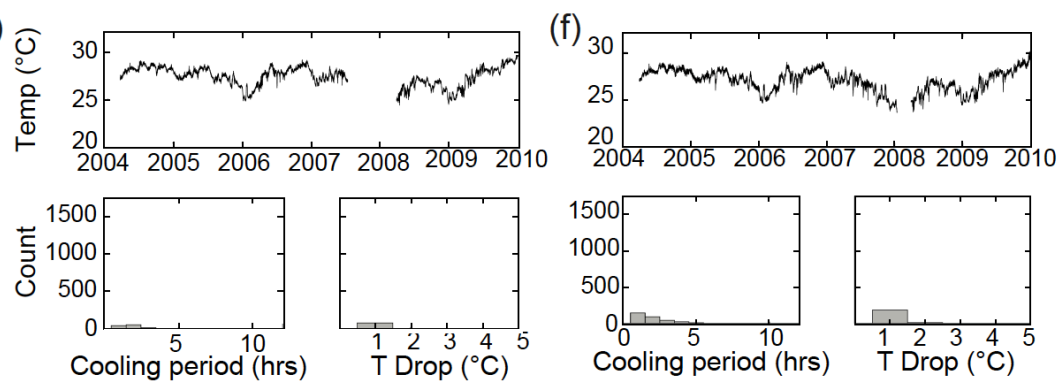

Figure 2. (a) Benthic community spatial dominance around the circumference of the fore reef habitat ( $8-20 \mathrm{~m}$ depth) at Jarvis Island quantified from towed-diver digital image surveys in 2006, 2008, and 2010. Spatial dominance is defined as the benthic group with the highest percent cover at that location. There are distinct ecotones around the island, defined as transition points between two regions of spatial dominance, particularly for hard plating coral, macroalgae, and crustose coralline algae (CCA). $(\mathrm{b}-\mathrm{f})$ High-resolution $\left(0.002^{\circ} \mathrm{C}\right.$ accuracy) reef-level temperature time series and the number of cooling events (by event duration) and their associated magnitude. Note the large number of cooling events on the west coast where hard corals dominate, compared to a low number of cooling events where either macroalgae or turf algae dominate. (g) Sub-surface temperature (solid line) captured by the diver-operated tow board during a circumnavigation of the island and the concurrent gradient in surface wave power (dashed line). 

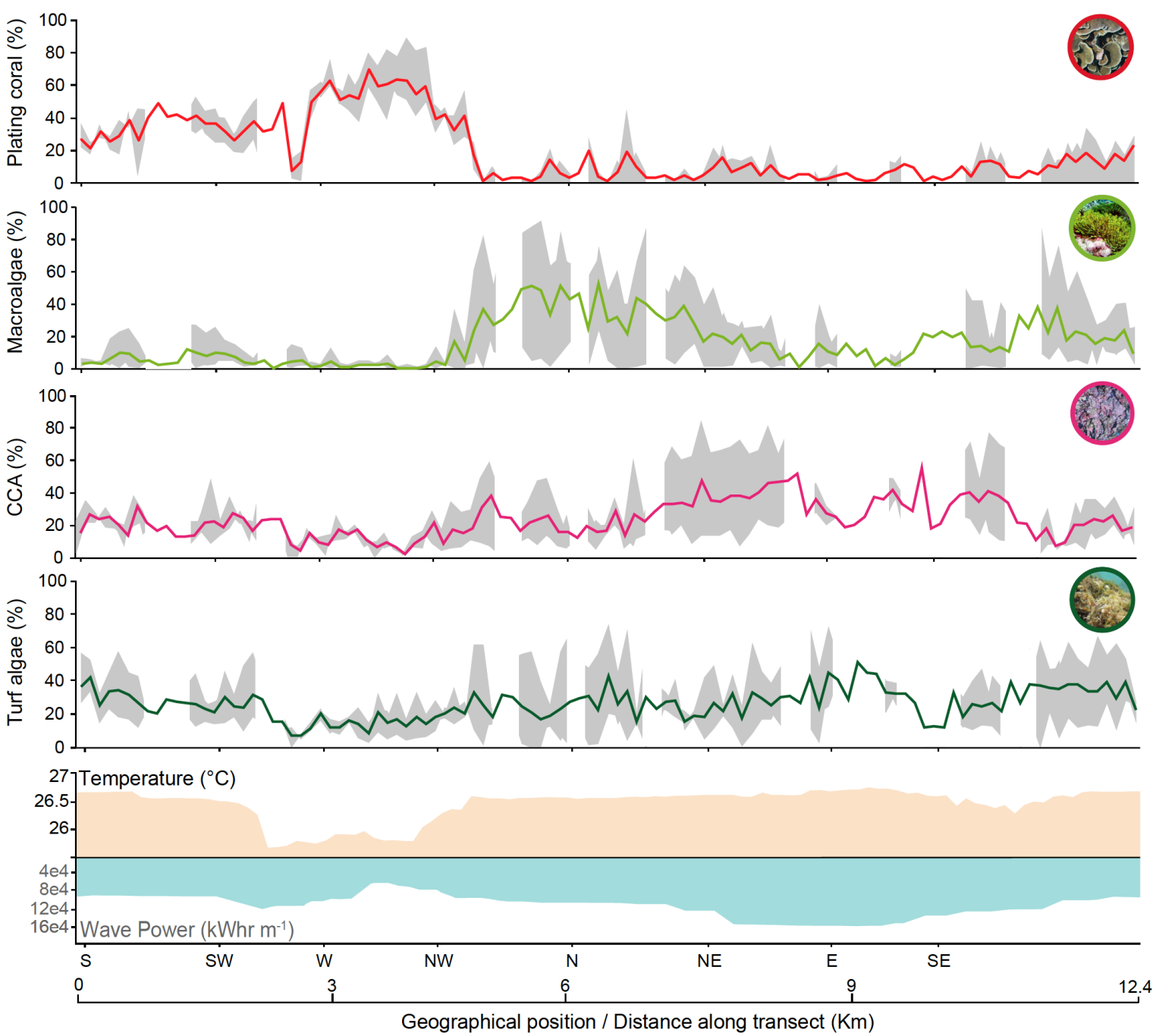

Figure 3. Benthic community seascapes around the $12.4 \mathrm{~km}$ circumference of Jarvis Island. Data are as in Fig. 2a but expanded to show the fine-scale spatial shifts in the percent cover of benthic competitors. The solid line in each case represents the mean cover (across all three survey years), with the temporal range in percent cover at each location shown in grey. The white spaces indicate where spatial replication failed our prerequisite of grid cells needing to contain $\geq 4$ benthic images in each of the three survey years. 


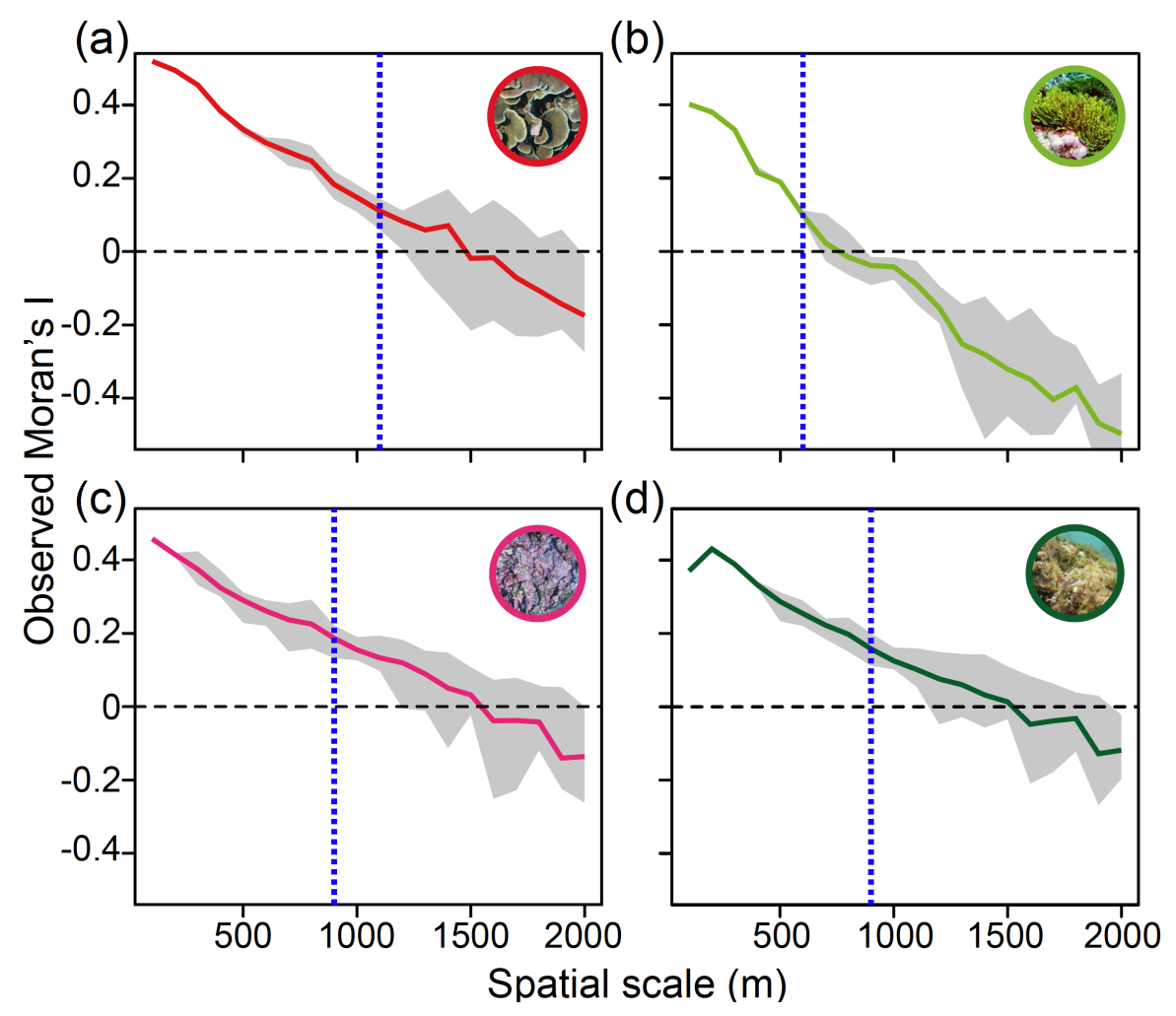

Figure 4. Patterns of spatial autocorrelation in the percent cover of plating coral (a), macroalgae (b), crustose coralline algae (c) and turf algae (d) at Jarvis Island. The observed Moran's I (OMI) value (solid line) indicates deviations from a random distribution (0 value horizontal dotted line) as either increasingly clustered (+ values) to increasingly dispersed (values). The range in OMI value at any particular scale depending on the starting location for the spatial averaging (i.e., the phase - see methods section) is shown. The vertical dotted line indicates the scale at which the OMI fails to differ significantly from random $(\mathrm{p} \geq 0.05)$. 

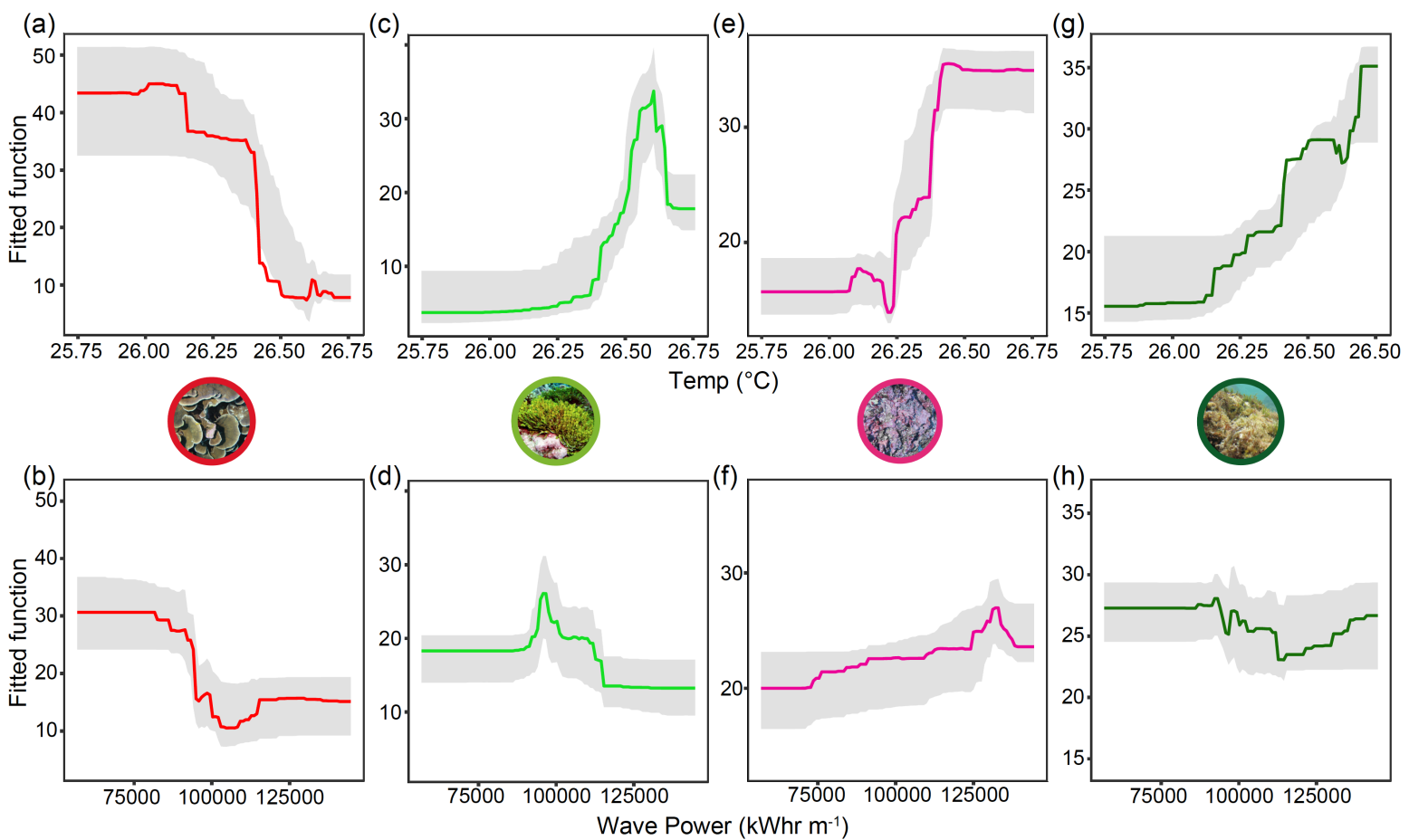

Figure 5. Partial dependency response plots from boosted regression tree (BRT) analyses relating spatial variations in subsurface temperature (Temp, $\left.{ }^{\circ} \mathrm{C}\right)$ and integrated surface wave power (Wave power, $\mathrm{kWh} \mathrm{m}^{-1}$ ) to concurrent changes in the percent cover ( $\mathrm{y}$-axis) of plating hard coral $(a, b)$, turf algae $(c, d)$, crustose coralline algae $(e, f)$, and macroalgae $(g, h)$. Solid colored lines represent the BRT fitted function with $95 \%$ confidence interval shown in grey (i.e., model uncertainty). 
Table 1. Boosted regression tree (BRT) model results, including optimal parameter settings, predictive performance, and relative influence of the two physical drivers (sub-surface temperature, as a proxy for localized upwelling, and integrated surface wave power) on spatial variations in the relative cover of benthic functional groups around the circumference of Jarvis Island. CCA, crustose coralline algae.

\begin{tabular}{lcccc}
\hline & Plating Coral & Macroalgae & CCA & Turf Algae \\
\hline Model parameters & & & & \\
Tree complexity & 3 & 5 & 1 & 4 \\
Learning rate & 0.001 & 0.0001 & 0.001 & 0.0001 \\
Bag fraction & 0.8 & 0.8 & 0.7 & 0.8 \\
Number of trees & 5400 & 24100 & 3300 & 18100 \\
Mean total deviance & 436.8 & 242.9 & 136.2 & 81.1 \\
CV deviance (CVD) & 68.5 & 67.5 & 49.9 & 42.0 \\
CVD Standard Error & 17.1 & 10.1 & 10.2 & 4.6 \\
CVD explained (\%) & $\mathbf{8 4 . 3}$ & $\mathbf{7 2 . 2}$ & $\mathbf{6 3 . 4}$ & $\mathbf{4 8 . 2}$ \\
\hline & & & & \\
Relative influence of predictors (\%) & & & & \\
Sub-surface temperature & 81.8 & 79.5 & 78.4 & 89.8 \\
Surface wave power & 18.1 & 20.5 & 21.6 & 10.2 \\
\hline
\end{tabular}

